See discussions, stats, and author profiles for this publication at: https://www.researchgate.net/publication/317139787

\title{
Micro-Raman analysis on the combined use of ammonium oxalate and ammonium phosphate for the consolidation and protection of carbonate stone artifacts: Micro-Raman analysis on the c...
}

Article in Journal of Raman Spectroscopy · May 2017

DOI: 10.1002/jss.5150

CITATIONS

8

6 authors, including:

Iacopo Osticioli

Italian National Research Council

60 PUBLICATIONS 878 CITATIONS

SEE PROFILE

Salvatore Siano

Italian National Research Council

184 PUBLICATIONS 1,648 CITATIONS

SEE PROFILE

Some of the authors of this publication are also working on these related projects:

PIMAS: Portable Instant Mineral Analysis Systems (EIT-RM) View project

Project Laser treatments in conservation of cullturall heritage View project
READS

120

Paolo Matteini

Italian National Research Council

112 PUBLICATIONS 1,631 CITATIONS

SEE PROFILE 
The published version of this article is available a this link: https://doi.org/10.1002/jrs.5150

Micro-Raman analysis on the combined use of ammonium oxalate and ammonium phosphate for the consolidation and protection of carbonate stone artifacts

\author{
Iacopo Osticioli, ${ }^{\mathrm{a}}$ Guido Botticelli, ${ }^{\mathrm{b}}$ Paolo Matteini, ${ }^{\mathrm{a}}$ Salvatore Siano, ${ }^{\mathrm{a}}$ Roberto Pini, ${ }^{\mathrm{a}}$ Mauro Matteini ${ }^{\mathrm{c}^{*}}$ \\ anstitute of Applied Physics "Nello Carrara" (IFAC), National Research Council, via Madonna del \\ Piano 10, 50019 Sesto Fiorentino, Italy \\ ${ }^{\mathrm{b}}$ Freelance conservator-restorer, Sesto Fiorentino, Italy \\ ${ }^{\mathrm{c}}$ Institute for Valorization and Conservation of Cultural Heritage (ICVBC), National Research Council, \\ via Madonna del Piano 10, 50019 Sesto Fiorentino, Italy \\ corresponding author: mmatteini@,inwind.it
}

\begin{abstract}
Ammonium oxalate $\left(\left(\mathrm{NH}_{4}\right)_{2} \mathrm{C}_{2} \mathrm{O}_{4}\right)$ and more recently ammonium phosphate $\left(\left(\mathrm{NH}_{4}\right)_{2} \mathrm{HPO}_{4}\right)$ are used as inorganic agents in the conservation of cultural heritage for protection and consolidation of carbonate stone artifacts. In this work we carry out a Raman investigation on the efficacy of a combined use of them. In particular, AmOx followed by DAP, DAP followed by AmOx and a DAP+AmOx mixture are applied on tablets of pure $\mathrm{CaCO}_{3}$ as well as on degraded marble samples. Then, cross-sections of samples are analyzed in depth from surface to bulk. Characteristic differences in penetration depth of these agents and distribution of their products of interaction with the substrate are detected and discussed. The analysis of the results takes into consideration several aspects including solubility and interaction dynamics between reaction products as well as the peculiar morphological features of the artifact, which are evidenced to play a significant role in treatment choice.
\end{abstract}

\title{
Keywords
}

Raman spectroscopy mapping, optical detection, hydroxyapatite, whewellite, Carrara marble

\section{Introduction}

For decades compliance with the "reversibility" criterion has been demanded in the conservation of cultural assets. This definitely responded to a need for caution in case the conservation treatment should not meet the expectations over time or should prove even adverse for the work of art. Unfortunately, it has become apparent that, reversibility is not practicably sustainable for consolidation treatments of outdoor stone artifacts. " In such cases, instead of "reversibility", "compatibility" and "durability" have become the main goals to pursue in order to safeguard the integrity of the works of art over time. In this context, since the mid-1990s a number of treatments mainly aimed at preserving the carbonate stone artifacts have been developed. ${ }^{2-3}$ These type of artifacts are indeed the most vulnerable toward environmental factors and in particular toward acid rain and condensation 
phenomena, which are frequently encountered in urban environments. In particular treatments based on the passivating/ protective action of ammonium oxalate $\left(\left(\mathrm{NH}_{4}\right)_{2} \mathrm{C}_{2} \mathrm{O}_{4}, \mathrm{AmOx}\right)$ and on the consolidating effect of di-ammonium phosphate $\left(\left(\mathrm{NH}_{4}\right)_{2} \mathrm{HPO}_{4}\right.$, DAP) have been proposed over the last two decades. 4-5 These inorganic agents show similar hydrophilic properties as well as a high affinity for limestones. In both treatments a moderate amount of calcium ions in the superficial layers of the artifact are involved in the formation of highly insoluble products, in turn developing strong chemical resistance and effective consolidating and protective capabilities.

The application of AmOx on the surface of carbonate stones generates whevellite (Ca-oxalate monohydrate) and / or weddellite (Ca-oxalate dihydrate), which are species commonly found as thin films on the surface of many artefacts. These are formed on stone monuments of various kinds including limestone over centuries and millennia, which proves their high compatibility. ${ }^{6}$ Calcium oxalates are not only insoluble under neutral $\mathrm{pH}$ conditions, but keep unaltered down to 2-3 $\mathrm{pH}$ values. In this framework, the treatment with AmOx provides an effective passivation against acid attack to the outer layers of the limestone artifacts, in turn preserving their durability in urban atmosphere. The AmOx treatment, which has been developed in the second half of $90 \mathrm{~s}^{7}$, shows also consolidating properties and thus has found further application in particular contexts, such as when marble is degraded to "sugary" texture. ${ }^{8}$

However, AmOx generally does not penetrate sufficiently in depth into the stone. ${ }^{9}$ For this reason, about ten years later a new treatment resembling the mechanism of AmOx and based on the use of ammonium phosphates has been proposed, leading to a much higher consolidating capability in terms of tenacity and treatment depth. Among different types of ammonium phosphates, the di-ammonium form has been considered the most convenient because of the mild alkalinity of its aqueous solutions as well as of the prevalent formation of hydroxyapatite (among the various calcium phosphates that it forms by interaction with calcium of the artifact). It is worth noting that hydroxyapatite, as very durable and compatible material, is the main constituent of bones and teeth where often coexists with calcium carbonate and also of the shells of some marine animals. ${ }^{10}$ Importance of hydroxyapatite as inorganic consolidant for damaged carbonate stones has been recently demonstrated. ${ }^{11-12}$

AmOx and DAP have been applied since 1999 and 2010, respectively, in a number of restoration projects for protection and consolidation of outdoor works of art (as facades, marble and limestone statues, frescoes, etc..). ${ }^{13-15}$ Afterwards, these products have received approval from conservatorrestorers in the field and attention has been recently posed in establishing whether these treatments are compatible with each other and, if this is the case, to what extent and to what application modes ${ }^{16}$. In particular, their combined use on monuments, where consolidation and protection are equally pursued, is becoming increasingly popular among stone conservator-restorers.

In this work, an investigation on the effectiveness of different application methodologies of AmOx and DAP is carried out. In particular, considerations concerning both the simultaneous and sequential use of these products on degraded marble are provided for the first time. For this purpose, micro-Raman spectroscopy is exploited for establishing the distribution inside calcareous substrates of Ca-oxalates and Ca-phosphates formed upon the application of the consolidation/protection treatments. The 


\section{Materials and methods}

Three different application methodologies of AmOx and DAP were tested: the first approach consists in performing the consolidation treatment with DAP followed by protection with AmOx; the second in protecting with AmOx followed by consolidation with DAP; the third in the simultaneous use of the two agents dissolved in the same solution. From an operative point of view, the first approach appears the most logical providing first deeper consolidation in the stone and then surface protection. The third approach appears attractive in order to avoid a double application, in turn resulting in time and cost savings.

Pure $\mathrm{CaCO}_{3}$ tablets were used as homogeneous carbonatic matrices, which can be prepared with high reproducibility thus allowing a trustworthy comparison among different treatments. A 5\% solution of DAP and a solution of 5\% AmOx were initially prepared as well as a mixture of $\mathrm{AmOx}(5 \% \mathrm{w} / \mathrm{v})$ and DAP $\left(4 \%\right.$ w/v). First, $\mathrm{CaCO}_{3}$ tablets were treated with DAP, AmOx and AmOx/DAP mixture separately: for this purpose the surface was covered with a cellulose poultice soaked with these solutions for $24 \mathrm{~h}$. Samples were then dried in oven at $40{ }^{\circ} \mathrm{C}$, washed in pure water for $1 \mathrm{~h}$ to remove excess of reactants and dried again in oven. Then consolidation followed by a protection treatment (and vice versa) was considered. For this purpose, $\mathrm{CaCO}_{3}$ tablets were first subjected to separated DAP and to AmOx treatment for $24 \mathrm{~h}$ followed by a drying/washing cycle. Then, the samples were treated with AmOx or DAP, respectively, for additional $24 \mathrm{~h}$ followed by another drying/washing cycle. The concentration of the salt solutions as well as the methodology adopted for applying them are in line with those employed by the operators in the conservation field. An overview of the treatments performed is summarized in Table 1. 
Table 1. Treatments on $\mathrm{CaCO}_{3}$ tablets.

\begin{tabular}{|c|c|c|}
\hline Tablet $\mathrm{N}^{\circ}$ & Name & Treatment \\
\hline 1 & $\mathrm{AmOx}$ & $\begin{array}{ll}- & 24 \mathrm{~h} \text { AmOx }(5 \% \mathrm{w} / \mathrm{v}) \text { poultice } \\
- & \text { drying }\left(40^{\circ} \mathrm{C}\right) \\
- & \text { lh washing } \\
- & \text { drying }\left(40^{\circ} \mathrm{C}\right)\end{array}$ \\
\hline 2 & DAP & $\begin{array}{ll}- & 24 \mathrm{~h} \text { DAP }(5 \% \mathrm{w} / \mathrm{v}) \text { poultice } \\
- & \text { drying }\left(40^{\circ} \mathrm{C}\right) \\
- & 1 \mathrm{~h} \text { washing } \\
- & \text { drying }\left(40^{\circ} \mathrm{C}\right)\end{array}$ \\
\hline 3 & MIX & $\begin{array}{ll}- & 24 \mathrm{~h} \text { DAP }(4 \% \mathrm{w} / \mathrm{v}) / \mathrm{AmOx}(5 \% \mathrm{w} / \mathrm{v}) \\
& \text { poultice } \\
- & \text { drying }\left(40^{\circ} \mathrm{C}\right) \\
- & \text { 1h washing } \\
- & \text { drying }\left(40^{\circ} \mathrm{C}\right)\end{array}$ \\
\hline 4 & $\mathrm{AmOx} \rightarrow \mathrm{DAP}$ & $\begin{array}{ll}\text { - } & 24 \mathrm{~h} \text { AmOx }(5 \% \mathrm{w} / \mathrm{v}) \text { poultice } \\
- & \text { drying }\left(40^{\circ} \mathrm{C}\right) \\
- & 1 \mathrm{~h} \text { washing } \\
- & \text { drying }\left(40^{\circ} \mathrm{C}\right) \\
- & 24 \mathrm{~h} \text { DAP }(5 \% \mathrm{w} / \mathrm{v}) \text { poultice } \\
- & \text { drying }\left(40^{\circ} \mathrm{C}\right) \\
- & 1 \mathrm{~h} \text { washing } \\
- & \text { drying }\left(40^{\circ} \mathrm{C}\right)\end{array}$ \\
\hline 5 & $\mathrm{DAP} \rightarrow \mathrm{AmOx}$ & $\begin{array}{ll}\text { - } & 24 \mathrm{~h} \text { DAP }(5 \% \mathrm{w} / \mathrm{v}) \text { poultice } \\
\text { - } & \text { drying }\left(40^{\circ} \mathrm{C}\right) \\
- & 1 \mathrm{~h} \text { washing } \\
- & \text { drying }\left(40^{\circ} \mathrm{C}\right) \\
- & 24 \mathrm{~h} \text { AmOx }(5 \%) \text { poultice } \\
- & \text { drying }\left(40^{\circ} \mathrm{C}\right) \\
- & 1 \mathrm{~h} \text { washing } \\
- & \text { drying }\left(40^{\circ} \mathrm{C}\right)\end{array}$ \\
\hline
\end{tabular}

Treatments of samples from parts of an ancient heavily degraded Carrara marble object were similarly performed. These samples were preliminarily washed in pure water in order to dissolve soluble impurities as well as to remove superficial sulfated parts partly detached.

Raman measurements were performed under an XPlora Horiba micro-Raman instrumentation equipped with three laser excitation sources. In particular, experiments on $\mathrm{CaCO}_{3}$ tablets were carried out using a $532 \mathrm{~nm}$ laser wavelength, a 10× objective, and diffraction grating of $1800 \mathrm{~g} / \mathrm{mm}$ (spectra were collected using an accumulation time of $10 \mathrm{~s}$ ). Whereas, for Carrara marble samples a laser excitation wavelength at $785 \mathrm{~nm}$ was preferred to minimize fluorescence signals frequently noted at shorter excitation wavelengths. In this case, a diffraction grating of $1200 \mathrm{~g} / \mathrm{mm}$ and a $50 \times$ objective were employed. Measurements on cross-sections of $\mathrm{CaCO}_{3}$ tablets were conducted by moving the 
microscope stage from the surface to the bulk and acquiring spectra by steps of $100 \mu \mathrm{m}$. Six Raman scans per tablet were registered in order to gather a reliable information. Raman mapping on crosssections of marble sample was performed on a $0.18 \times 1.4 \mathrm{~mm}^{2}$ area including a total of 45 acquisitions moving from the surface to the interior of the sample.

\section{Results}

Figure 1 shows the Raman spectra acquired at different depth on cross-sections of the $\mathrm{CaCO}_{3}$ tablets treated with solutions of pure AmOx (Fig. 1a) and pure DAP (Fig. 1b). We may note that calcium oxalate is detected mainly in the form of whewellite $\left(\mathrm{CaC}_{2} \mathrm{O}_{4} \cdot \mathrm{H}_{2} \mathrm{O}\right)$ down to a depth of $1.2 \mathrm{~mm}$. On the other hand, calcium phosphate is detected in the form of hydroxyapatite $\left[\mathrm{Ca}_{5}\left(\mathrm{PO}_{4}\right)_{3} \mathrm{OH}\right]$ down to a depth of $2 \mathrm{~mm}$. The formation equilibrium of mono- and di-hydrate forms of Ca-oxalates i.e. whewellite and weddellite $\left(\mathrm{CaC}_{2} \mathrm{O}_{4} \cdot 2 \mathrm{H}_{2} \mathrm{O}\right)$ strongly depends on environmental parameters, and mainly on temperature, humidity and $\mathrm{pH}^{18}$ However, whewellite is more stable in standard environmental conditions whereas weddellite shows a tendency to transform in whewellite. ${ }^{20}$ Raman modes of Caoxalates in Fig. 1a were assigned accordingly to Hernanz et al.. ${ }^{21}$

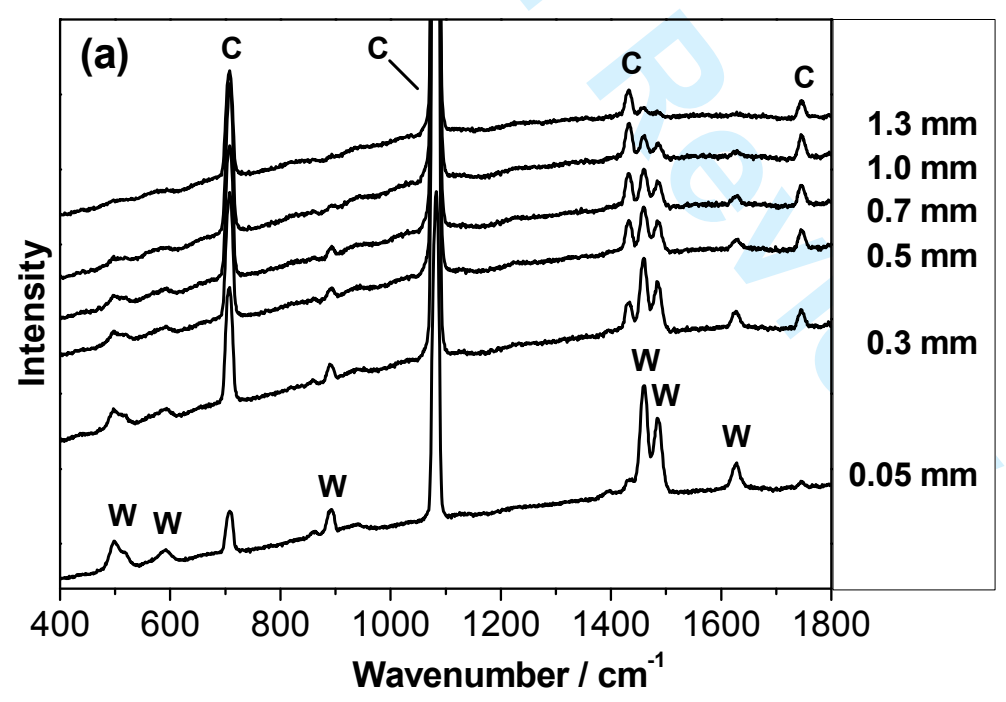




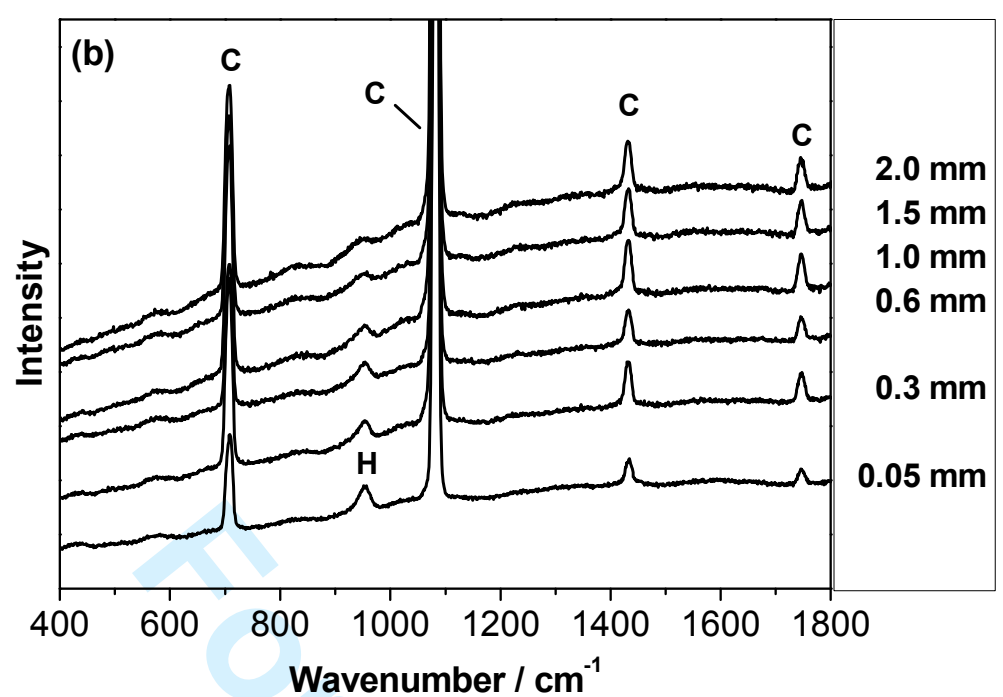

Figure 1. Raman analysis of $\mathrm{CaCO}_{3}$ tablets at different depths after AmOx (a) and DAP (b) treatments. C: calcite. W: whewellite. H: hydroxyapatite.

The Ca-phosphate band at $954 \mathrm{~cm}^{-1}$ is ascribed to the symmetric stretching mode of the tetrahedral $\mathrm{PO}_{4}$ group $\left(v_{1}(\mathrm{P}-\mathrm{O})\right)$ and is characteristic of hydroxyapatite mineral. ${ }^{22} \mathrm{We}$ can exclude the formation of other Ca-phosphates such as $\mathrm{Ca}\left(\mathrm{H}_{2} \mathrm{PO}_{4}\right)_{2} \cdot \mathrm{H}_{2} \mathrm{O}$ (monohydrate calcium phosphate), $\mathrm{Ca}\left(\mathrm{HPO}_{4}\right) \cdot 2 \mathrm{H}_{2} \mathrm{O}$ (dicalcium phosphate dehydrate or brushite), $\mathrm{Ca}_{3}\left(\mathrm{PO}_{4}\right)_{2}$ (tricalcium phosphate), and $\mathrm{Ca}_{8} \mathrm{H}_{2}\left(\mathrm{PO}_{4}\right)_{6} .5 \mathrm{H}_{2} \mathrm{O}$ (octacalcium phosphate) because their vibrational profile significantly differ from that of hydroxyapatite. $^{23-27}$ Besides the formation of the latter after DAP treatment of carbonatic substrates is in accordance with the literature. ${ }^{10}$

The treatment with a mixed DAP/AmOx solution led to the sole formation of calcium oxalate, down to a depth of $0.9 \mathrm{~mm}$ (Fig.2a). At the same time any presence of Ca-phosphate phase can be excluded. Similarly, Raman measurements carried out on $\mathrm{CaCO}_{3}$ tablets subjected to the AmOx $\rightarrow$ DAP treatment (Fig. $2 \mathrm{~b}$ ) revealed the exclusive presence of calcium oxalate and down to $1 \mathrm{~mm}$. 

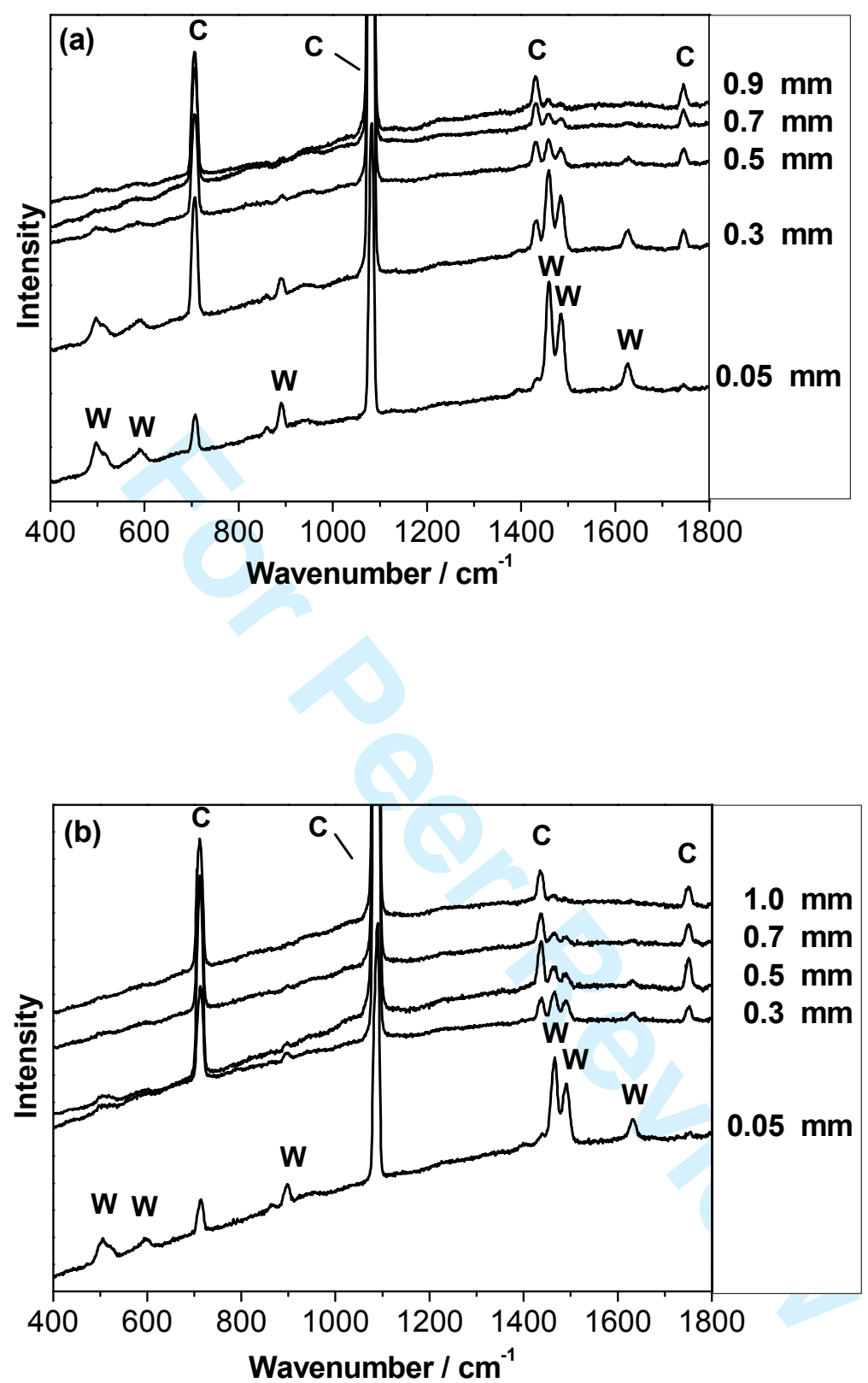

Figure 2. Raman spectra of $\mathrm{CaCO}_{3}$ pellets after AmOx/DAP MIX (a) and AmOx $\rightarrow D A P(b)$ treatments at different depths. C: calcite. W: whewellite.

Finally, $\mathrm{CaCO}_{3}$ tablets treated by $\mathrm{DAP} \rightarrow \mathrm{AmOx}$ sequence (Fig.3b) revealed the presence of both calcium oxalate and calcium phosphate. In particular, calcium oxalate signals can be observed down to a depth of $1.3 \mathrm{~mm}$. Conversely, calcium phosphate signals appear very weak within the first $0.2 \mathrm{~mm}$ then they grow gradually and remain visible down to $2.5 \mathrm{~mm}$ of depth. 


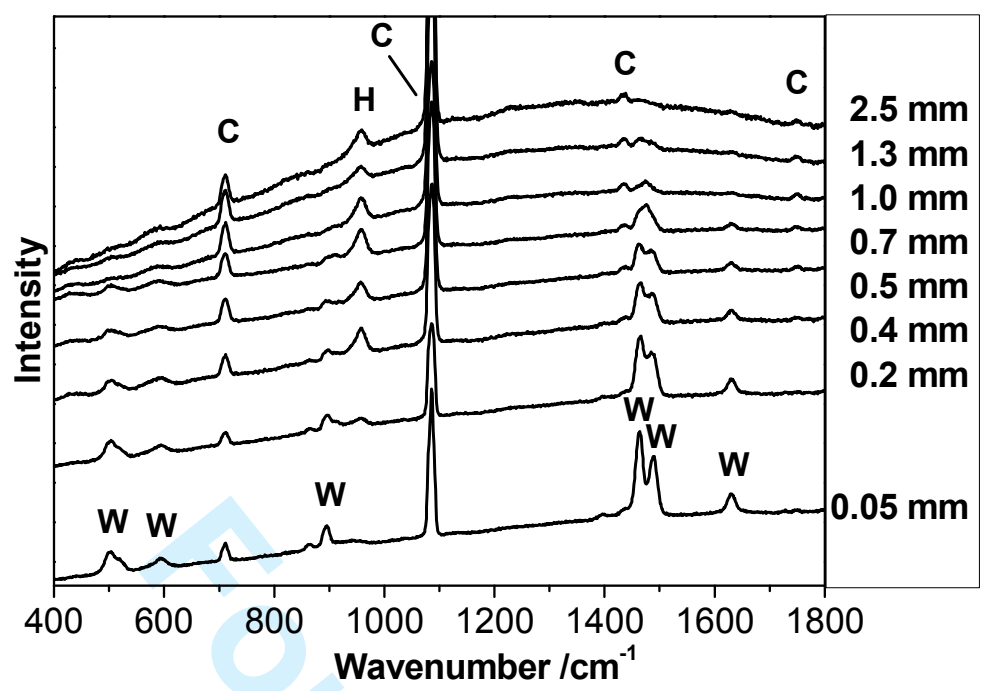

Figure 3. Raman spectra of $\mathrm{CaCO}_{3}$ pellets after $\mathrm{DAP} \rightarrow A m \mathrm{O}$ treatment at different depths. $\mathrm{C}$ : calcite. W: whewellite. H: hydroxyapatite.

Raman measurements from degraded Carrara marble samples treated by the MIX and AmOx $\rightarrow$ DAP modalities provided comparable results with those achieved for $\mathrm{CaCO}_{3}$ tablets. In particular, the presence of calcium oxalate was detected down to a depth of around $1 \mathrm{~mm}$ for both treatments (Fig. 4). Moreover, in sample areas treated with the AmOx $\rightarrow$ DAP sequence where the stone was degraded in large extent, calcium oxalate was detected down to a depth of almost $2 \mathrm{~mm}$ (Fig. 4c).

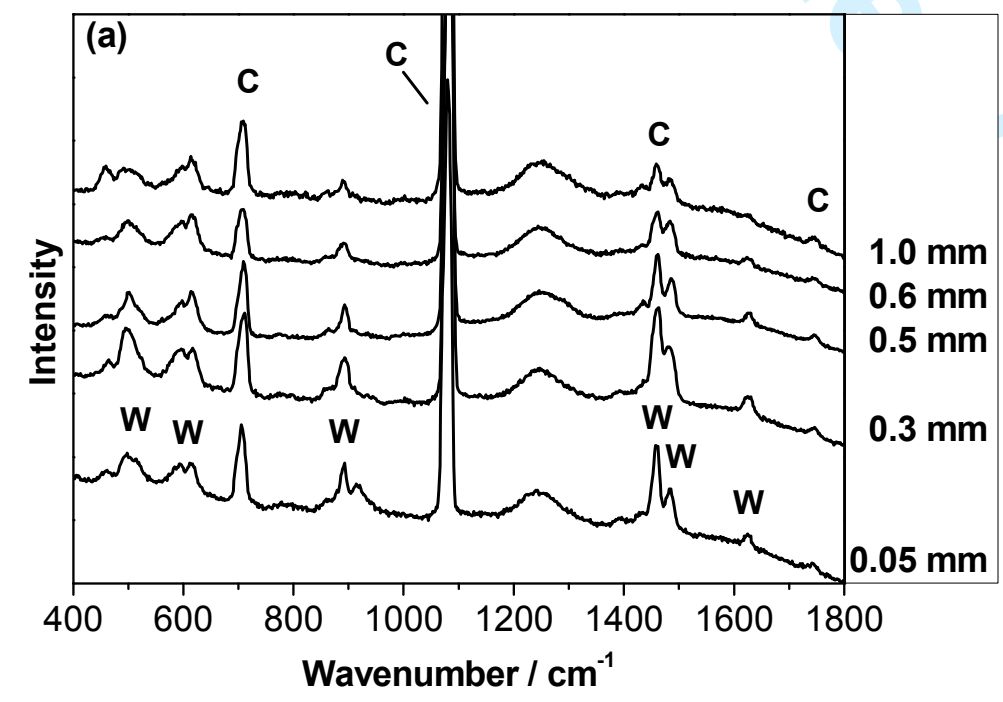



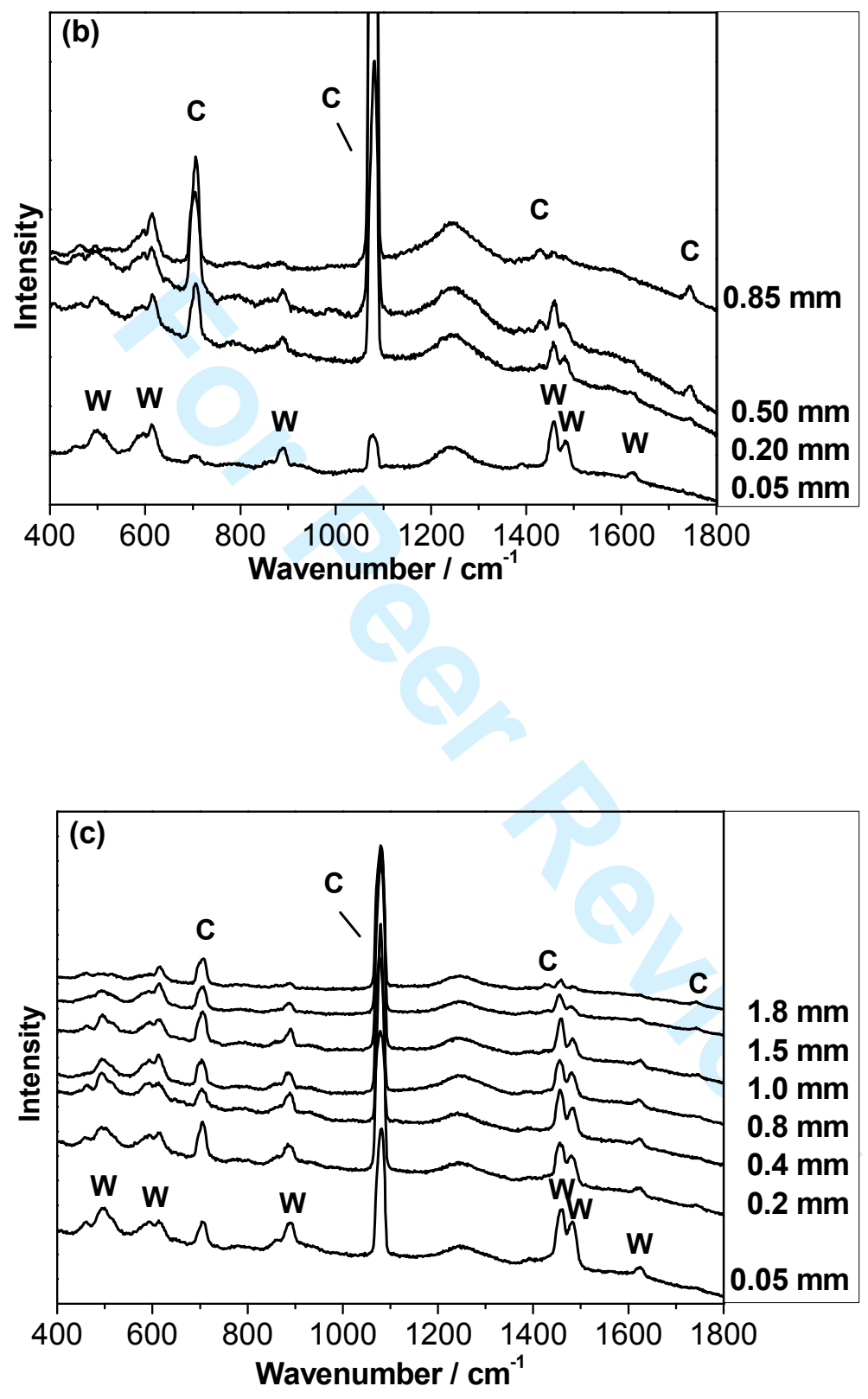

Figure 4. Raman spectra of degraded marble samples after AmOx/DAP MIX (a) and AmOx $\rightarrow D A P(b, c)$ treatments at different depths. C: calcite. W: whewellite. When marble degradation is significant (c), the penetration depth of oxalate is deeper. 
The Raman analysis on degraded marble treated with $\mathrm{DAP} \rightarrow \mathrm{AmOx}$ revealed an inhomogeneous distribution of calcium phosphate in the bulk. This outcome can be ascribed to a strong point-to-point variability in porosity, grains dimension and morphology of the substrate. In turn, performing a continuous Raman mapping along a predetermined direction in depth was not possible. Thus, in order to achieve a complete overview of the distribution of calcium phosphate throughout the substrate, elemental map of phosphorus by means of Scanning Electron Microscopy (SEM) was performed. Figure 5 shows a back-scattered electrons (BS)-SEM picture (left) of a cross-section of marble sample after $\mathrm{DAP} \rightarrow \mathrm{AmOx}$ treatment along with the corresponding SEM-elemental map of the phosphorous content (right). Here, phosphorus appears spotty distributed in the substrate down to a $\sim 2.5 \mathrm{~mm}$ depth and can be associated to the presence of hydroxyapatite as revealed by Raman analysis (see spectra at $\mathrm{z}$ $=0.1$ and $0.8 \mathrm{~mm}$ in Figs. $6 \mathrm{a}$ and $6 \mathrm{~b}$ ). In the Raman spectra of the same samples, Ca-oxalates were detected in the form of whewellite down to a depth of $\sim 1 \mathrm{~mm}$, while they were absent at larger depth (see Raman spectra at $\mathrm{z}=1.2 \mathrm{~mm}$ and $1.8 \mathrm{~mm}$ in Figs. $6 \mathrm{c}$ and $6 \mathrm{~d}$ ).
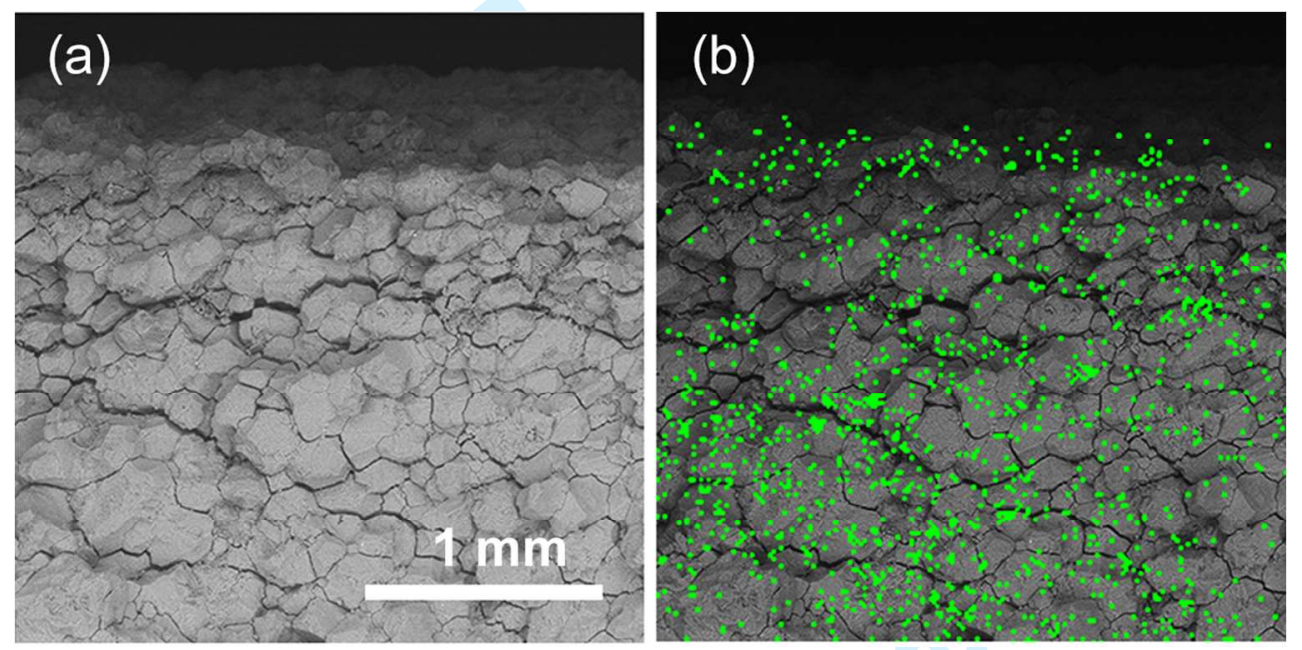

Figure 5. BS-SEM images of a cross-section of a degraded marble sample after DAP $\rightarrow$ AmOx treatment (a) and its corresponding phosphorus content map (b). 

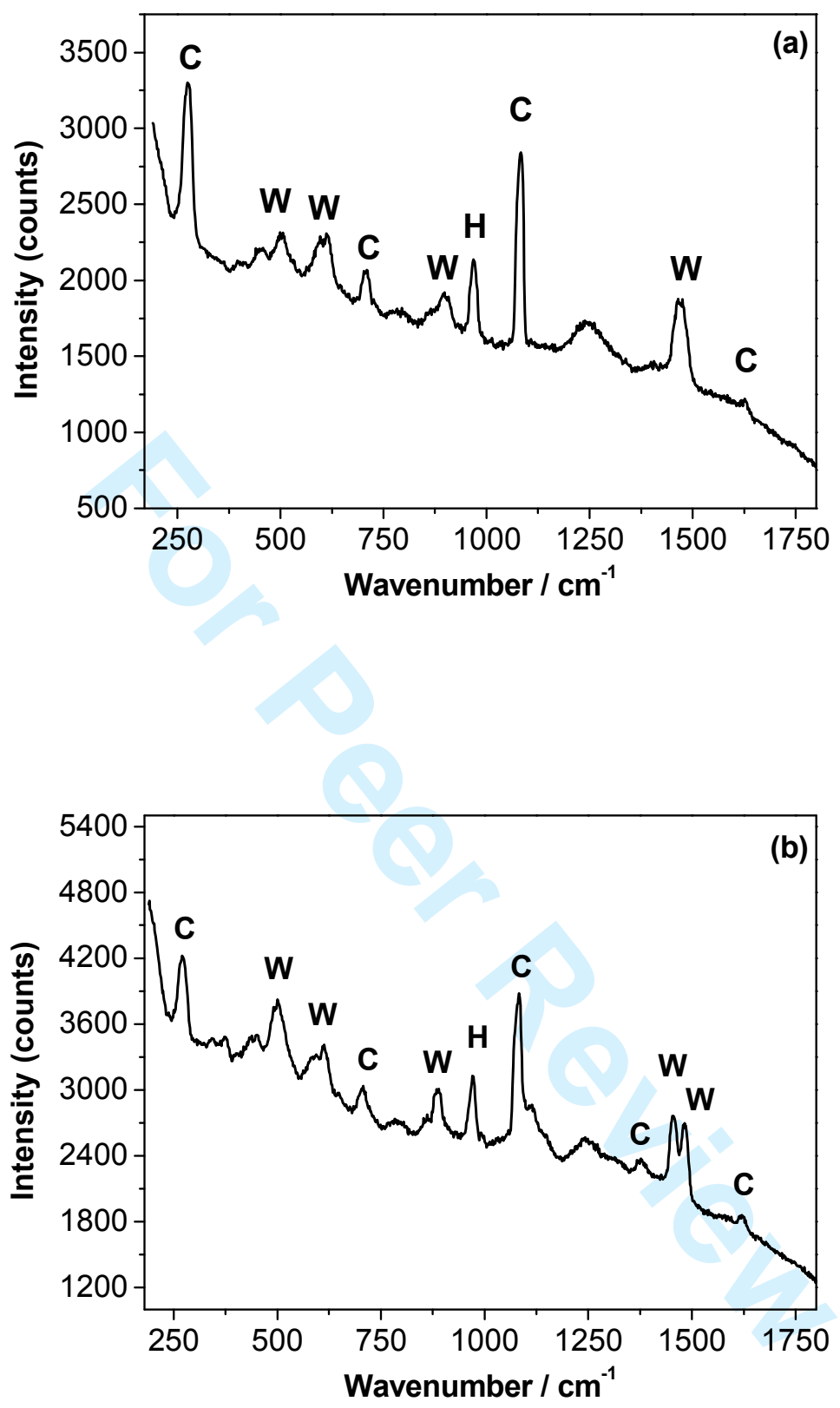

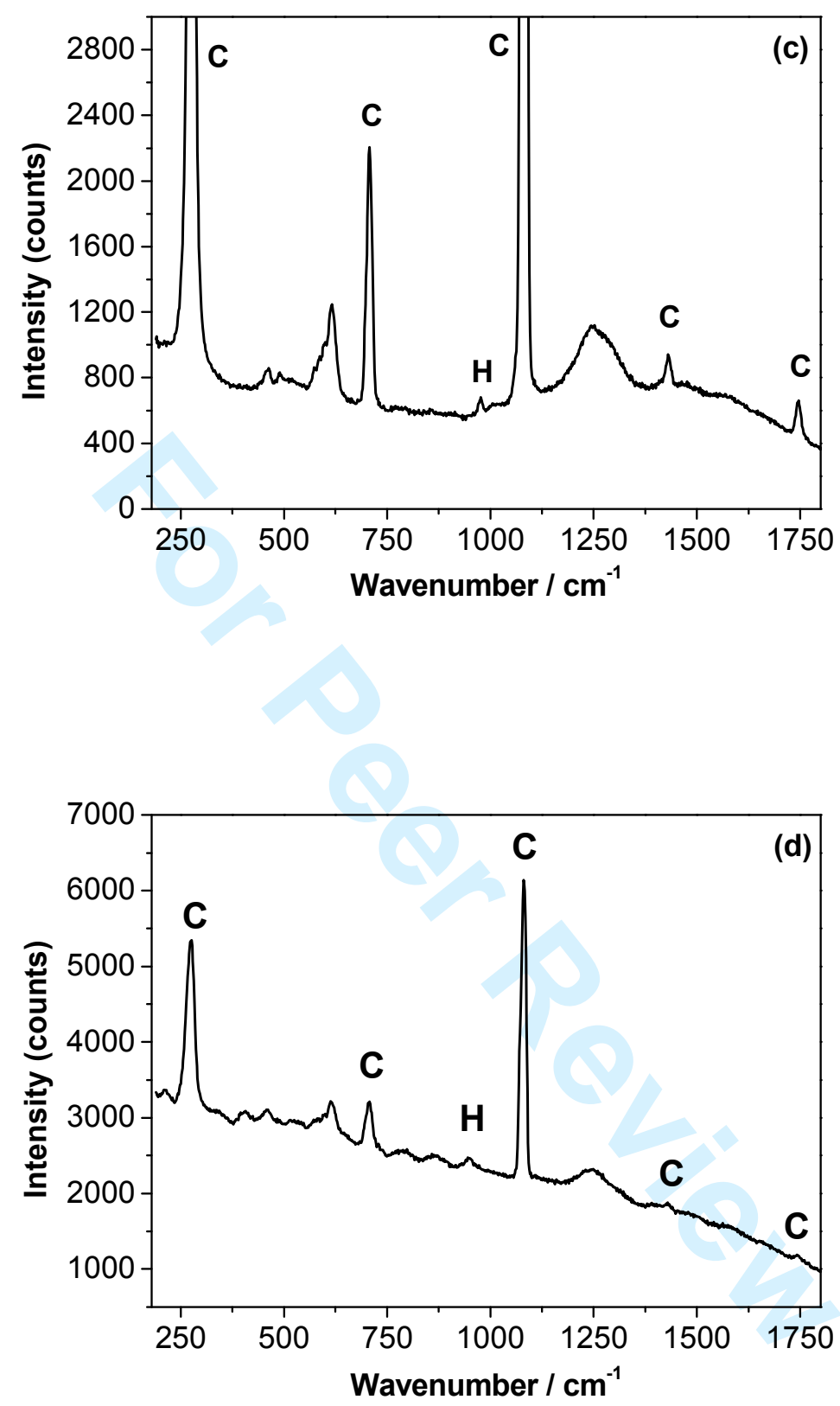

Figure 6. Selected Raman spectra at different depths of a degraded marble sample after $D A P \rightarrow A m O x$ treatment: $z=$ (a) $0.1 \mathrm{~mm}$, (b) $0.8 \mathrm{~mm}$, (c) $1.2 \mathrm{~mm}$, (d) $1.8 \mathrm{~mm}$. C: calcite. W: whewellite. H: hydroxyapatite.

Unfortunately, elemental mapping of Ca-oxalate by using SEM is not feasible since calcium, oxygen and carbon are the major constituents of carbonate stone as well. Thus, to gain insights into the distribution of Ca-oxalate throughout the stone a Raman mapping of the $1440 \mathrm{~cm}^{-1}$ mode of whewellite was accomplished. The results of the mapping on a $0.18 \times 1.4 \mathrm{~mm}^{2}$ area (Fig. 7) clearly reveal that, on the opposite of phosphate, the content of Ca-oxalates gradually decreases within $1 \mathrm{~mm}$ beneath the 


\section{Discussion}

Raman results obtained for $\mathrm{CaCO}_{3}$ tablets after treatment with different combination of AmOx and DAP were in good agreement with those of similarly treated samples of degraded Carrara marble. Caoxalates, mainly in the form of whewellite, were found homogeneously distributed from surface down to about $1 \mathrm{~mm}$ independently of the treatment performed. Larger penetration depths of AmOx were observed in strongly degraded areas of marble samples. Conversely, Ca-phosphates in the form of hydroxyapatite were found only when the DAP treatment was applied at first in the procedure. A plausible explanation of this behavior can be reached by taking into account the chemical properties of both DAP and AmOx and their reaction products with the carbonate stone. In particular: a) the final species formed by the preservation/consolidation treatment show different solubility according to the sequence: brushite $\left(\mathrm{Ksp}=1.86 \times 10^{-7}\right)>$ whewellite $\left(\mathrm{Ksp}=2.32 \times 10^{-9}\right)>$ hydroxyapatite $(\mathrm{Ksp}=6.8 \times$ $\left.10^{-37}\right)$; b) AmOx has a tendency to react more quickly than DAP with the calcium carbonate of the stone generating insoluble products within the first $\sim 1 \mathrm{~mm}$ from the surface, which in turn significantly reduce the surface porosity (without, however, altering the wettability); c) brushite $\left(\mathrm{CaHPO}_{4} \cdot 2 \mathrm{H}_{2} \mathrm{O}\right)$ is considered a precursor in the precipitation process of hydroxyapatite ${ }^{28}$ and the basic environment provided by the carbonate matrix favors its conversion into hydroxyapatite by few hours. Therefore, in the $\mathrm{AmOx} \rightarrow$ DAP treatment, after application of $\mathrm{AmOx}$, the main part of $\mathrm{Ca}^{2+}$ ions of the surface becomes rapidly involved in the formation of whevellite and is not more available for further reaction with DAP. Thus when DAP is successively applied, $\mathrm{Ca}^{2+}$ ions available on the surface are scarce. Furthermore, the formation of whevellite reduces considerably the porosity. Thus, the DAP solution can hardly spread throughout the stone matrix because of the reduced porosity encountered. As a consequence the reaction products of DAP are not detected by Raman analysis of samples treated with 
the AmOx $\rightarrow$ DAP modality. If we consider now the samples treated with the DAP + AmOx mixture, the action of AmOx prevails on that of DAP, similarly as above, because of the lower Kps of whewellite with respect to brushite and of the consequent porosity reduction that hampers DAP diffusion inside the stone substrate. In this case, again, Ca-phosphates were not internally detected. Conversely, in DAP $\rightarrow$ AmOx treatment, DAP is applied at first and brushite, the medium solubility phosphate phase that is expected to form initially, has enough time to freely diffuse throughout the stone, and it is ultimately replaced by hydroxyapatite. AmOx, which is applied later, is able to react with the $\mathrm{Ca}$ ions of brushite to generate whewellite in the first hundred microns from the surface, but cannot capture $\mathrm{Ca}$ ions already involved in the formation of hydroxyapatite, because of its minimal solubility. As a matter of fact this was the only case in which Raman analysis was able to clearly detect the formation of Ca-phosphates. Overall we note that further considerations regarding different penetration depth and distribution of DAP and AmOx can be similarly made on the basis of the material porosity, ${ }^{29}$ on the formation mechanism of apatite and oxalate crystals ${ }^{22,30}$ as well as on their mutual interactions. ${ }^{31}$

\section{Conclusions}

Three different combinations of DAP and AmOx were applied on calcareous substrates and evaluated as agents for consolidation/protection. Raman spectroscopy of cross sections revealed the formation of Ca-oxalates mainly in the form of whewellite both on the surface and throughout the bulk of the samples. The distribution of whewellite proved homogenous at fixed distances inside the substrates and followed similar decreasing gradients independently from the typology of the treatment applied. Presence of Ca-oxalates was detected down to a depth of $\sim 1 \mathrm{~mm}$, which became larger on highly degraded regions of marble substrate. Ca-phosphates in the form of hydroxyapatite were detected at greater depth (down to $2.5 \mathrm{~mm}$ ), confirming better consolidating properties of DAP with respect of AmOx. However, calcium phosphate, in the form of highly insoluble hydroxyapatite formed only when DAP was applied at first, followed or not by AmOx. Therefore, when the conservation aim is realizing both consolidation and protection of calcareous artefacts (statue, bas-relief, stone façade, fresco) the DAP followed by the AmOx treatment appears the most effective according to the results obtained by the Raman spectra. Finally, although some hypotheses were formulated in order to understand the mutual interaction dynamics between $\mathrm{Ca}$-oxalates and $\mathrm{Ca}$-phosphates, further research is needed to better clarify this aspect.

\section{Acknowledgements}

Authors would like to thank the Opificio delle Pietre Dure of Florence for kindly giving the degraded marble samples used for the analysis. 


\section{References}

[1] J. Delgado Rodrigues, in Historical Constructions, Proc. Int. Seminar on Historical Constructions, Guimarães, 2001, pp. 3-14.

[2] P. Baglioni, L. Dei, F. Pique, G. Sarti, E. Ferroni, Stud. Conserv. 1997; 42, 43.

[3] E. Hansen, E. Doehne, J. Fidler, J. Larson, B. Martin, M. Matteini, C. Rodriguez-navarro, E. S. Pardo, C. Price, A. De Tagle, J. M. Teutonico, N. Weiss, Rev. Coserv. 2003; 4, 13.

[4] M. Matteini, S. Rescic, F. Fratini, G. Botticelli, Int. J. Archit. Herit. 2011; 3058, 717.

[5] D. Mudronja, F. Vanmeert, K. Hellemans, S. Fazinic, K. Janssens, D. Tibljas, M. Rogosic, S. Jakovljevic, Appl. Phys. A 2012; 111, 109.

[6] C. Conti, M. Casati, C. Colombo, M. Realini, L. Brambilla, G. Zerbi, Spectrochim. Acta A 2014; 128,413 .

[7] M. Matteini, S. Giovannoni, Restauratorenblätter 1996; 16, 95.

[8] E. Sassoni, G. Graziani, E. Franzoni, Mater. Des. 2015; 88, 1145.

[9] C. Conti, C. Colombo, G. Festa, J. Hovind, E. P. Cippo, E. Possenti, M. Realini, J. Cult. Herit. 2016; 19, 463.

[10] E. Possenti, C. Colombo, D. Bersani, M. Bertasa, A. Botteon, C. Conti, P. P. Lottici, M. Realini, Microchem. J. 2016; 127, 79.

[11] E. Sassoni, S. Naidu, G. W. Scherer, J. Cult. Herit. 2011; 12, 346.

[12] F. Yang, D. He, Y. Liu, N. Li, Z. Wang, Q. Ma, G. Dong, Appl. Phys. A 2016; 122, 1.

[13] B. Doherty, M. Pamplona, C. Miliani, M. Matteini, A. Sgamellotti, B. Brunetti, J. Cult. Herit. 2007; $8,186$.

[14] A. E. Charola, S. A. Centeno, K. Normandin, J. Archit. Conserv. 2014; 16, 29.

[15] M. Balonis-Sant, X. Ma, I. Kakoulli, Acs. Sym. Ser. VIII. 2013; 22, 419.

[16] M. Matteini, C. Colombo, G. Botticelli, M. Casati, C. Conti, R. Negrotti, M. Realini, in Built Heritage, Monitoring Conservation Management 2013; pp. 1278-1286.

[17] H. G. M. Edwards, D. W. Farwell, R. Jenkins, M. R. D. Seaward, J. Raman Spectrosc. 1992; 23, 185.

[18] R. L. Frost, Anal. Chim. Acta 2004; 517, 207.

[19] G. Sauer, W. Zunic, J. Durig, R. Wuthier, Calcif. Tissue Int. 1994; 54, 414. 
[20] C. Conti, C. Colombo, M. Matteini, M. Realini, G. Zerbi, J. Raman Spectrosc. 2010; 41, 1254.

[21] A. Hernanz, J. M. Gavira-Vallejo, J. F. Ruiz-lópez, J. Optoelectron. Adv. M. 2007; 9, 512.

[22] S. Koutsopoulos, J Biomed Mater Res. 2002; 62, 31.

[23] J. Xu, D. F. R. Gilson, I. S. Butler, Spectrochim. Acta A 1998; 54, 1869.

[24] F. Casciani, R. A. Condrate. Sr, Spectrosc. Lett. 2006; 12, 699.

[25] A. Jillavenkatesa, R. A. Condrate Sr, Spectrosc. Lett. 2006, 31,1619.

[26] U. Posset, E. Locklin, R. Thull, W. Kiefer, J. Biomed. Mater. Res. 1998; 40, 640.

[27] B. O. Fowler, M. Markovi, W. E. Brown, Chem. Mater. 1993; 5, 1417.

[28] M. S.-A. Johnsson, G. H. Nancollas, Crit. Rev. Oral. Biol. M. 1992; 3, 61.

[29] P. López-Arce, L. S. Gomez-Villalba, L. Pinho, M. E. Fernández-Valle, M. Á. de Buergo, R. Fort, Mater. Charact. 2010; 61, 168.

[30] C. Conti, M. Casati, C. Colombo, E. Possenti, M. Realini, G. Diego Gatta, M. Merlini, L. Brambilla, G. Zerbi, Spectrochim. Acta Part A Mol. Biomol. Spectrosc. 2015; 150, 721.

[31] P. K. Grover, D.-S. Kim, R. L. Ryall, Mol. Med. 2002; 8, 200. 